\title{
Phytoprotection
}

\section{Research Challenges and Needs for Safe Use of Microbial Organisms - an Industrial Perspective in USA}

\section{Robert J. Cilbulsky}

Volume 79, numéro 4, 1998

OECD Workshop - Sustainable Pest Management, Safe Utilization of New Organisms in Biological Control. Montréal, Québec, Canada. September 27-30, 1998.

Atelier de l'OCDE - Gestion durable des ennemis des cultures, Utilisation sécuritaire de nouveaux organismes de lutte biologique. Montréal, Québec, Canada. 27-30 Septembre 1998.

URI : https://id.erudit.org/iderudit/706154ar

DOI : https://doi.org/10.7202/706154ar

Aller au sommaire du numéro

Éditeur(s)

Société de protection des plantes du Québec (SPPQ)l

ISSN

0031-9511 (imprimé)

1710-1603 (numérique)

Découvrir la revue

Citer cet article

Cilbulsky, R. J. (1998). Research Challenges and Needs for Safe Use of Microbial Organisms - an Industrial Perspective in USA. Phytoprotection, 79(4), 36-39.

https://doi.org/10.7202/706154ar d'utilisation que vous pouvez consulter en ligne. 


\title{
Research Challenges and Needs for Safe Use of Microbial Organisms - an Industrial Perspective in USA
}

\author{
Robert J. Cibulsky, Ph.D.
}

Abbott Laboratories, North Chicago, Illinois USA

The overall goal for any commercial organization involved in the development of microbial organisms for agricultural, forestry, or vector control applications is profitability. Whether or not we agree with this perspective, it forms the core of our capitalist industrial system. The agricultural world is littered with the debris from commercial biocontrol product failures over the last twenty-five years. As described at previous professional meetings, there is a veritable "graveyard" of microbial product failures and all were ultimately linked to the inability to generate a consistent, profitable, product.

Once we accept the tenet of profitability as a key success factor for any organization involved in the commercial development of microbial organisms, we can stretch our thoughts to an assessment of the fundamental drivers impacting the commercial process. Without doubt, research and development are the basis for any successful microbial product. However, we presently exist in one of the most highly regulated industries, and as such, a large portion of current research and development is dedicated to meeting the numerous regulatory demands for any new product (organism). The one word that we must embrace, if microbial products are to find a niche in the future agricultural world, is "flexibility". Flexibility will be key to the registration of current and future products. If we are not willing to adapt to the individual characteristics of these products, then the future of microbials is almost certainly limited, if not eliminated entirely.

We presently face a number of issues beginning with the acceptance of $\mathrm{mi}$ crobial products as totally different from the classical chemical alternatives for which regulations were and still are primarily written and directed. Bacteria, fungi, viruses, protozoa, etc. are so distinctly different from each other that a common denominator for registration of these organisms is difficult to identify. As a result, this leads to difficult decisions when trying to express the active ingredient, specific activity, or formulation potency for product labeling. We are still grasping for the final understanding of how Bt works after thirty plus years of research. We can not afford to make a similar investment of resources for all the other microbial candidates.

The regulatory issues do not stop with identification of potency for a commercial label. We are also dealing with a number of additional labeling issues, such as spray drift, worker reentry intervals, and container disposal, all of which are most likely of critical importance for hazardous chemical products, but less likely to be problems for microbial products. If we are trying to encourage the use of microbial products, then we must adapt label requirements for these factors to promote their selection and use. These factors can be critical in today's forestry and vector (mosquito) control programs. Twenty 
years of experience in applications to forests and aquatic systems with microbial products should provide valuable insight to "acute and chronic" exposure that must not be overlooked. The same alarmist issues that are raised today as "concerns" are not any different than what was elevated within and outside the scientific community in the 1970 's. To our overall benefit, the "Andromeda strain" has not become a reality, or else the world would have been consumed by $\mathrm{Bt}$ or some other microbial product.

It may be difficult to determine if regulatory is the primary or secondary driver, but if it is not the first then product "efficacy" surely is the most critical driver. Today's farmer and future agricultural producers are provided with a buffet of alternatives for the control of problem pests (weeds, insects, plant diseases, etc.). To the greater extent, the majority of these options are highly effective products. As a result, the commercial grower has come to expect relatively few problems during the growing cycle of a particular crop. We may not be able to control the weather, but we can control the soil fertility, weeds, insects, and diseases that can adversely affect a grower's yield. Let's accept the fact that the typical grower is compensated for yield and in certain cases a high quality yield. Unless we can provide the grower with an efficacious microbial alternative to the currently available and usually reliable synthetic chemical products, then we are ultimately foreshadowing failure. We have historically failed to develop microbial products that are equivalent or superior to synthetic chemistry. This must change.

The third driver is primarily controlled by the commercial organization involved in the development of any microbial product. The driver is large scale production which eventually translates directly into the final product cost. Why are production and cost so important? Can cost be more important than safety concerns? The answer is simply that the grower is confronted with the same profitability motives that the commercial organization faces. If the grower can not produce a crop in a cost effective manner, then his future is certainly limited. As a result, the grower will generally accept the least expensive, effective option to control any problem that is encountered during the growing cycle of that crop. Unless there are significant financial rewards provided directly to the individual grower for the selection of less hazardous approaches or products, the grower will always default to the most cost effective option. This is not just human nature, but financial survival. With the exception of bacterial-based products, we have failed to develop cost effective production technology for the majority of microbial product candidates.

The net effect of these drivers can be summarized in one word, "expediency". Time is money and time becomes a key financial driver. However, what are the many factors that have impacted and continue to impact time or expediency in the development of microbial products?

We have already identified efficacy as a key objective for research and development programs. However, one of the key shortcomings for all microbial products has been the failure to develop a long term ( $>2$ year) stability profile for formulated commercial products. With the exception of Bt formulations, the majority of all microbial products are not viable for six months at room temperature storage conditions. This is a significant weakness that must be overcome if these products are to become acceptable options for the commercial grower. Widescale acceptance and global use of any product requires transportation, handling, and exposure to environmental extremes. What works in North America must also work in equatorial Africa.

Although we all acknowledge that one of our long term objectives is the protection of the overall environment, we must also accept the fact that the cost of evaluation of microbial products and their impact on similar ecosystems has become excessively expensive. For example, ecozone evaluations have been conducted with Bt products used for forest and vector control programs 
on a global scale, and frankly at an unacceptable cost in terms of time and money. There is some point when we must learn to accept the results generated from our guideline studies that have been identified for registration and not embark on or acquiesce to the "search for the Holy Grail approach" to environmental monitoring and assessment. Almost every nation appears to have developed a set of specific parameters to determine environmental acceptability. Unfortunately, few are the same. This will soon become financially untenable to manufacturers, if that time has not already arrived. If "harmonization" of these ecotoxicology and environmental requirements is the solution, then it is long overdue. The critical issue with microbials has not been safety related. We must shift our near and long term focus to the key drivers.

Human safety has been and should be the first priority for the evaluation and development of any microbial product. But, again we have taken scientific curiosity to extremes, with a good example being the current issue and debate surrounding enterotoxins and bacterial microbial products. Since many species can be significantly similar genetically, but at the same time physiologically and phenotypically different, then it is probable that two closely related bacterial species can also be substantially different. Although $\mathrm{Bt}$ manufacturers (registrants) have been required to complete a number of mammalian enterotoxin evaluations (rabbit ileal loop assay, monkey feeding study) in order to attain product registration, there is still a movement to create additional testing to further evaluate enterotoxins. This assault also fails to recognize the years of exposure of humans to $\mathrm{Bt}$, not only indirectly from soil exposure, but also directly on a number of food crops. At some point in time, we must accept the fact that "more is not always better" when it comes to additional testing. From 19961997 the residents of Auckland, New Zealand were exposed to more than forty successive sprays of Btk as a result of an urban forest insect eradication program. Outside of some "alarm- ist" complaints, the overall consensus from the Auckland Health officials indicated and reinforced the outstanding safety record of Btk products. When will we consider historical or corrobative evidence as an important factor in our final decision making process?

Microbial agents offer us another potential option for addressing the development of pest resistance on a global scale. Although microbial products may not be the complete answer, bacterial, fungal, and viral organisms offer diverse alternatives to classical synthetic chemistry. There is also a very fine line separating the use of these "active ingredients" as gene specific transformations in a number of agriculturally important crops and the potential loss of these agents due to the development of pest resistance. A thorough understanding of the implications of widespread resistance development to microbial products should be a research priority. However, this effort would be most effectively coordinated by an independent organization with broad-reaching authority. For a variety of reasons, most commercial organizations are severely limited in their ability to conduct "resistance directed" research under field conditions.

So where does that leave us today? We need to concentrate our research and development efforts on: 1) improving microbial product performance (efficacy); 2) identifying more costeffective production technology for all microbials; 3 ) develop improved shelflife (formulation stability $>2$ years at RT); 4) identify more active "strains and toxins" to keep pace with the everchanging performance benchmarks; 5) enhance "residual" efficacy or performance to mirror current alternatives. We must understand that microbial biocontrol agents will continue to face competition from transgenic plants and new pesticide chemistry, as well as other future technology. In biology and the business world, Darwinian principles will prevail.

Finally, we must be flexible and exercise significant doses of "common sense" when we are faced with challenges to a microbial regulatory system 
that has produced an outstanding record of human, animal, and environmental protection to the public for more than twenty years. There must be a point when more is not better and we must be willing to embrace that position.

\section{KEY QUESTIONS/ISSUES FOR DISCUSSION}

1. How can we develop flexibility in the regulatory labeling process to resolve issues concerning microbial potency, active ingredient, specific activity, spray drift, worker re-entry, etc. without the investment of significant commercial research resources?

2. Are the recommendations for additional safety research (e.g. microbial enterotoxins, ecozones) based on real scientific concerns or on socio-economic or political issues?
3. How can we stimulate specific research for the development of new production and formulation technology for microbial agents that will address the current weaknesses?

4. How can we encourage novel approaches to the identification of new microbial agents with the performance (efficacy) potential to replace existing products?

5. Can we utilize a permanent bipartisan committee comprised of academic, government, and industry members as a "sounding board" to address specific issues related to $\mathrm{mi}$ crobial product registration (e.g. enterotoxins, daphnia study requirements)?

6. How can we utilize some of the historical experience and evidence to educate the general public about the acceptability of microbial control agents for agricultural, forestry, and environmental health applications?

7. What can be done to eliminate the political boundaries that interfere with the harmonization of microbial registration guidelines? 